\title{
October 2021
}

$50 \mathrm{~s}, 60 \mathrm{~s}$, and 70 -Plus Age SPOTLIGHT

Most older adults move toward more digitally connected lives

The "tech cliff drop-off" is flattening as older adults continue to move toward more digitally connected lives regardless of age.

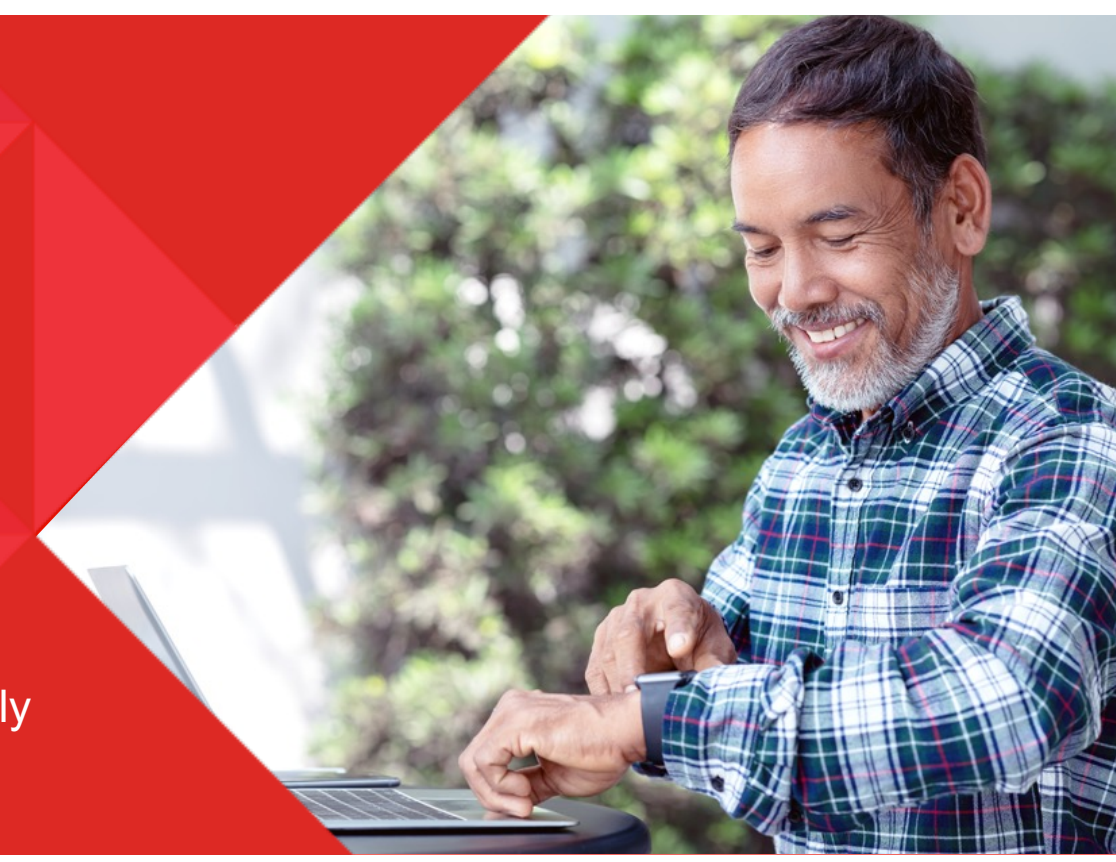

Perhaps driven by the need to connect with others and conduct activities from the safety of home due to the COVID-19 pandemic, ownership of and spending on technology devices among 50-plus adults has increased year-over-yeari and activities which were seldomly done online have seen a significant increase among this age group. It's too early to tell if these trends will continue once the pandemic is over, but adults 50-plus have demonstrated they can embrace new technologies and are willing to spend and use them more to bring ease and safety into their lives.

\section{Technology device ownership has increased year- over-year among adults $\mathbf{5 0 +}$, with smart TVs seeing the highest increase across all age bands}

In 2020, four in five (85\%) adults 50-plus own a smartphone, representing an eight-percentage-point increase from a year ago (77\%). While ownership remains highest among those 50-59 (92\%) and declines as age advances, with $85 \%$ of those $60-69$ and $77 \%$ of those $70+$ owning a smartphone, people 70+ saw the highest gain in ownership (15-percentage points) from a year earlier.

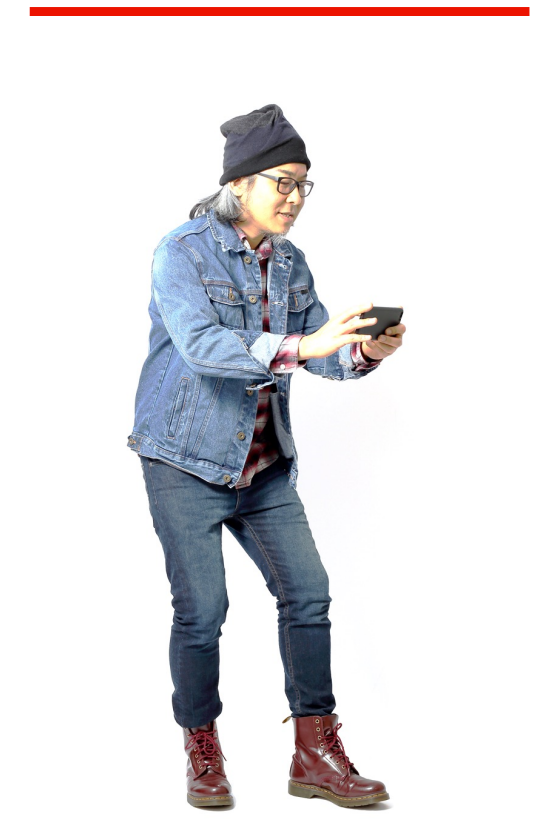

\section{A new study examines} technology ownership and online activity changes among adults 50-plus. 
Overall, Smart TV ownership increased significantly from 2019 (49\%) to 2020 (64\%). The biggest is seen among those in their 50's and 60's as it increased by 17 and 16 percentage points, respectively, compared to 11 percentage points among those $70+$. Nonetheless, the increase seen among the older cohort is significant as now one-half $(51 \%)$ of those $70+$ own such a device.

Tablets saw an increase in popularity, as well, as now more than one-half (56\%) of adults 50-plus own such a device, compared to less than one-half $(47 \%)$ who did so in 2019 . Three in five $(60 \%)$ of those $50-59$, own a tablet, compared to just over one-half of those in their 60's (54\%) and those $70+(53 \%)$. Perhaps this increase was fueled by the desire to stay connected with others due to the pandemic, and ease of a bigger screen for video chat, as frequency of use of tablets increased as well, especially among those $70+$. The current pandemic could be behind the higher frequency of use of tablets among those $70+$ as they are more likely to be physically isolated where two-thirds (69\%) use it daily, compared to one-half (52\%) of those in their 50's and 60's.

Wearables, like Fitbit and Apple Watch (27\%), and home assistant devices, like Amazon's Echo and Google Home (29\%), have seen a significant increase in ownership from 2019 (17\%, respectively) pushing adoption rates for both, over the one-quarter mark. Among those in their 50's, adoption rates of wearables (34\%) and home assistant devices is now over one-third (34\%) up from less than one-quarter the year before $(22 \%$ and $20 \%$, respectively). Those $70+$ saw gains of 15 percentage points for home assistant ownership (12\% in 2019 vs $27 \%$ in 2020) and nine-percentage-points for wearables (11\% in 2019 vs $20 \%$ in 2020) for the same time frame a year earlier.

While the frequency of use of those who own a wearable device did not increase, the daily frequency of use of those who own a home assistant device showed the highest increase year-over-year among all tech devices with an increase of nine-percentage-points (2019, $54 \%$ vs $2020,63 \%)$.

Ownership rates of smart home technology, like Nest thermostats and Ring doorbell cameras, still lag among people 50-plus compared to other types of technology. Nonetheless, a year-over-year increase was observed (10\% in 2019 vs $19 \%$ in 2020$)$.

\section{Technology ownership - 2020}
Total $(50+)$
50-59
60-69
$70+$

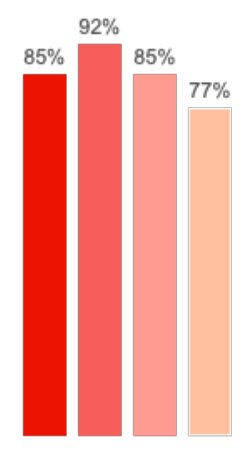

Smartphone

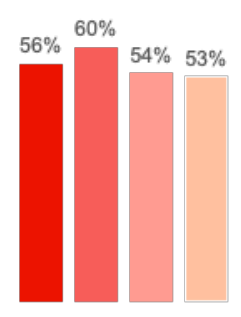

Tablet

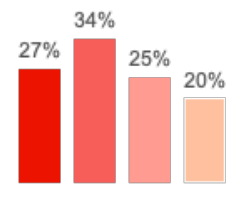

Wearable Device

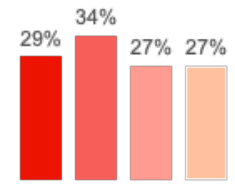

Home Assistant

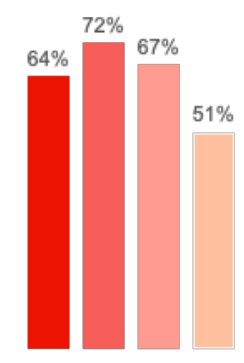

Smart TV 
A majority of people 50 -plus (63\%) feel confident when using technology, but one-half (54\%) admit they wish they had a better grasp of technology in general to allow them to more frequently and easily connect with others. Looking closer, it's the newer technologies like home assistants (25\%) and smart home tech (26\%) they wish they knew more about. A majority (72\%) would prefer to learn about new technology through their friends and family and two in five (39\%) say they would use more technology if they knew how to use it.

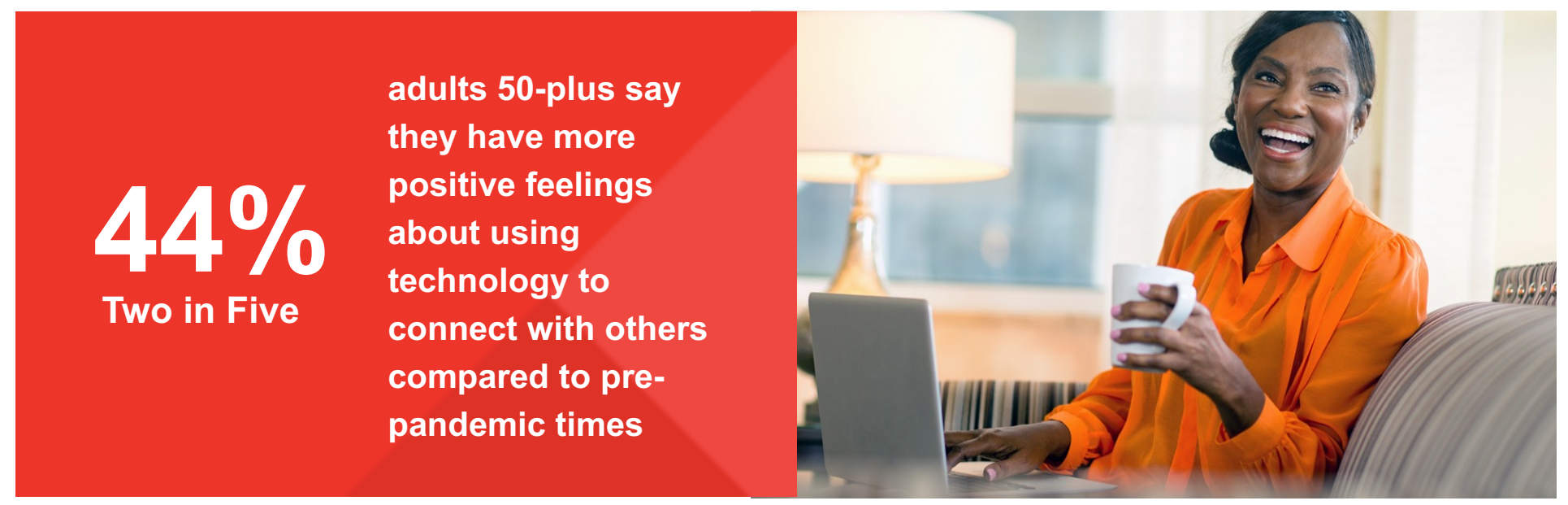

\section{On average, adults 50-plus increased their spend on tech with the biggest increase among people 50-59}

The top 5 purchases among people 50-plus between September 2019 and September 2020, were smartphones (35\%), Smart TVs (23\%), Bluetooth headset/ear buds (22\%), laptop computers (19\%), and tablets (15\%). Those in their 50's (45\%) and 60's (35\%) are more likely than those $70+(24 \%)$ to purchase a new smartphone. Those in their 50's are also more likely than older people to purchase Smart TVs (26\% - 50's, $21 \%-60$ 's, and 22\% - 70+), headsets (31\% - 50's, 19\% - 60's, and 15\% - 70+), and laptop computers (25\%50 's, $17 \%-60$ 's, and 14\% - 70+). However, it is those $70+$ who saw the biggest gains on most tech device ownership year-over-year.

Nonetheless, people 50-plus significantly increased their spend on technology year-over-year. On average, all age groups spent more tech devices, with those in their 50's increasing the most from 2019 and spending the most compared to those in their 60's or 70+.

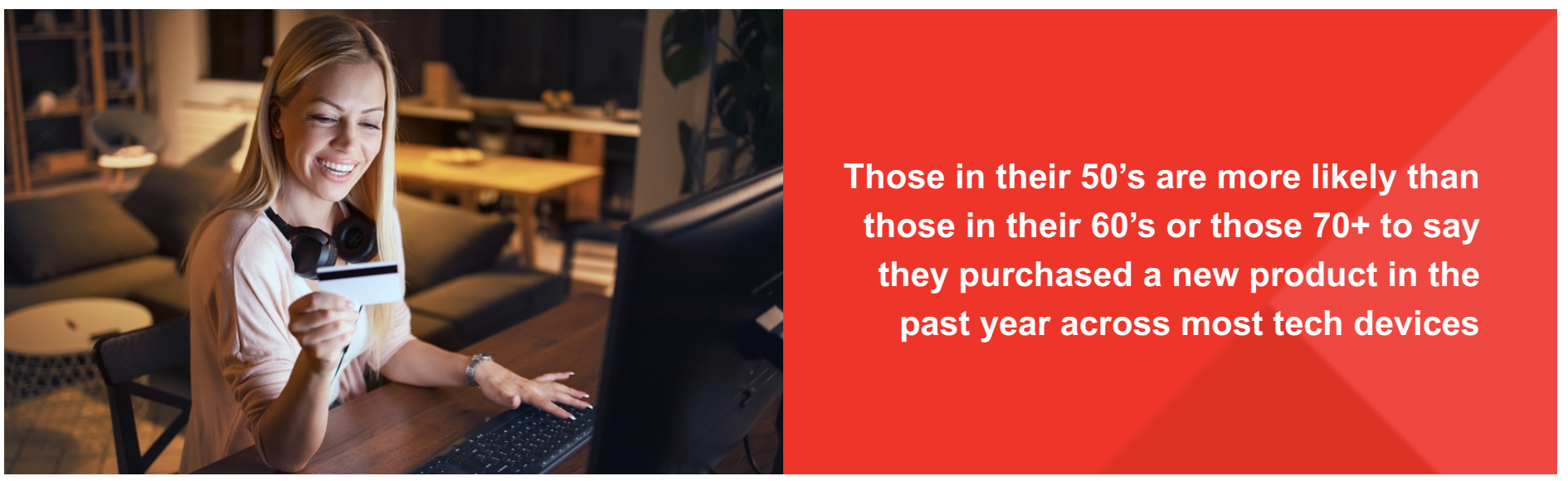




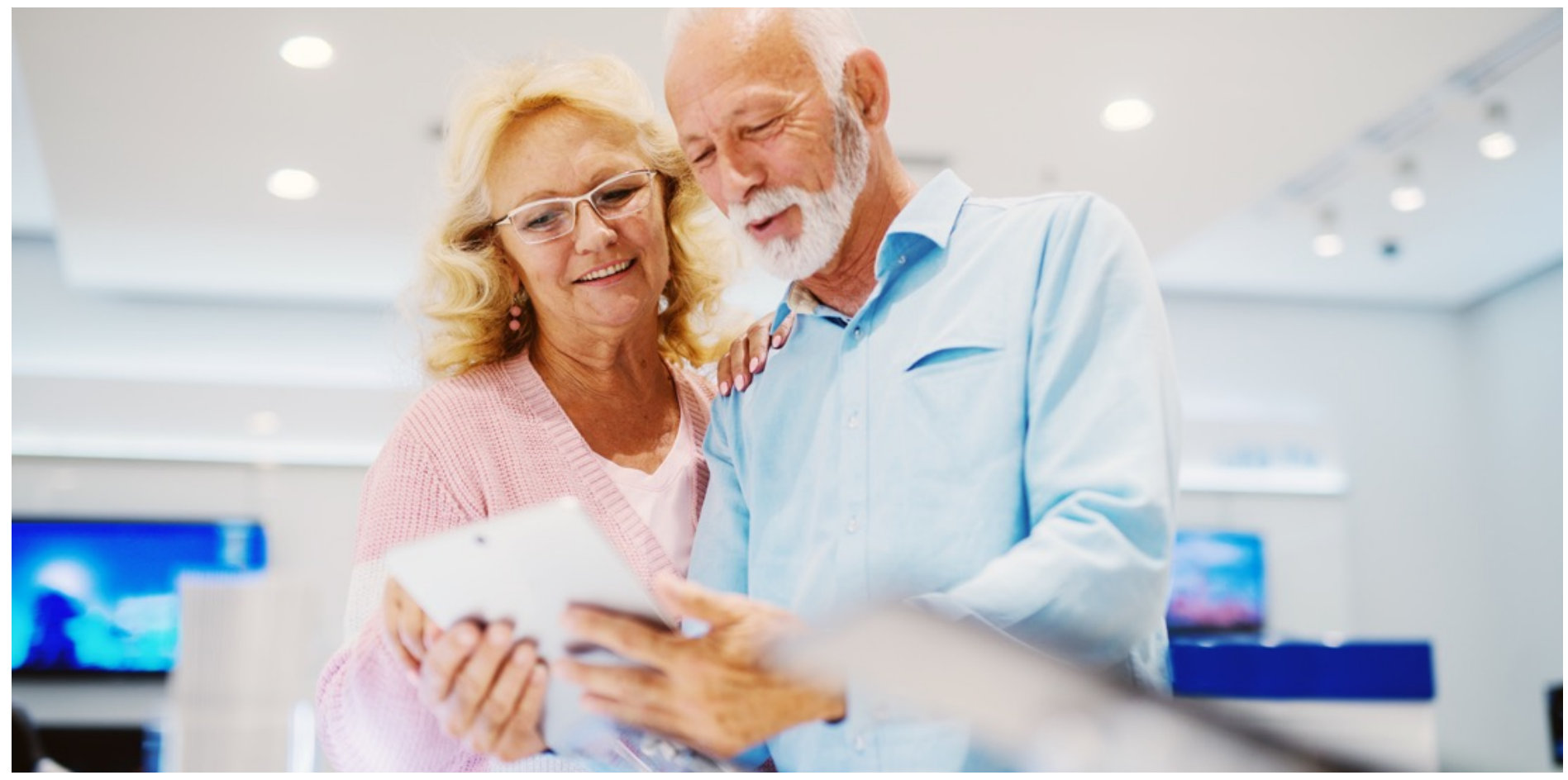

Average amount spent on technology by age

\section{0}

号

ֻ

$\stackrel{+}{\circ}$

\section{$\$ 1,481$}

$\$ 941$

$\$ 972$
2019

$\$ 542$

$\$ 339$

$\$ 270$

\section{Many older adults misunderstand privacy issues}

When it comes to technology adoption, there are some barriers keeping older adults from embracing new technology. Right behind cost (30\%), privacy concerns (24\%) and lack of knowledge (24\%) are at the top of the list of barriers that people say are stopping them from adopting technology.

While equal percentages of older adults are not confident what they do online remains private (50's 83\%, 60's $83 \%, 70+83 \%)$. Privacy is an issue ripe for consumer education. Overall, only two in five (43\%) understand correctly that having a website privacy policy still allows a site to share their information with other websites, and just half (53\%) know that an advertising agency is typically the "third party" in online privacy policy agreements.. Adults ages 70-plus are more likely to have incorrect assumptions about privacy than those in their 50's or 60's (correctly know privacy policies still allow sharing: 50's :46\%, 60's: 45\%, 70+: 39\%), (correctly know ad agencies are the "third party:" 50's: 53\%, 60's: 58\%, 70+: 47\%). 


\section{The transition to managing life with digital tools due to the pandemic might be driving the increase of activities done through a smartphone}

The pandemic of COVID-19 seems to have had an important effect on the type of activities adults 50-plus perform on their smartphones, either by necessity, or comfort. The use of a health track app increased significantly in 2020 from a year prior, especially for those in their 60 's and $70+(50$ s: $30 \%$ vs $24 \%, 60$ s: $25 \%$ vs $17 \%$, and $70+: 20 \%$ vs $9 \%$ ). Those in their 50's (49\%) and 60's (46\%) are also more likely to get health and fitness information through this device than their older peers $70+(35 \%)$. This could be a result of people trying to stay active and track their health while staying close to home.

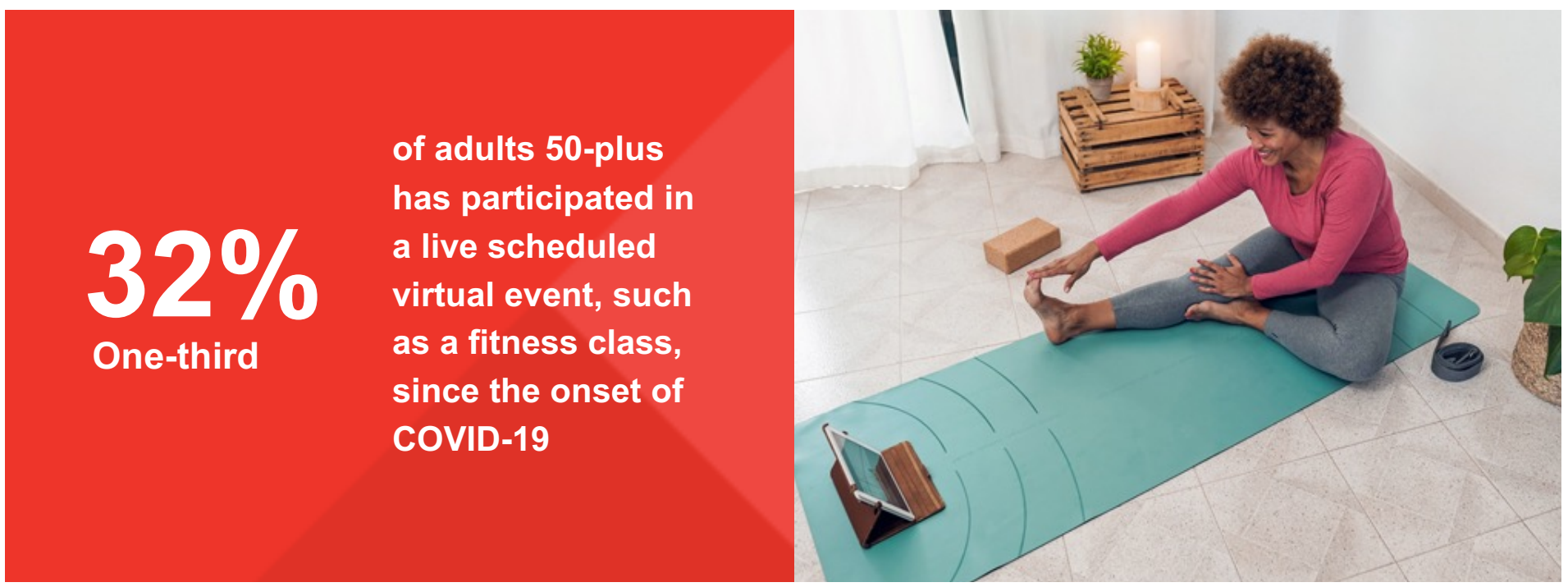

Other activities, like buying groceries online, experienced a significant increase as well, especially among people 50-59 as one-third (32\%) bought groceries this way in 2020 compared to only seven percent in 2019; although, fewer among those in their 60's (2019 4\% vs 2020 23\%) and 70+ (2019 2\% vs 2020 16\%) shopped this way. Making purchases online is most commonly done by those in their 50's (72\%), compared to those in their 60's (52\%) and 70+ (34\%), and, overall, for those 50+, this activity increased in 2020 as more than onehalf $(55 \%)$ have done so compared to one-third (34\%) in 2019.

Online banking saw a jump among people 50+, where almost two-thirds (65\%) of those in their 50's say they engaged in this activity on their smartphone in 2020, compared to less than one-half (39\%) who did so a year earlier. Those in their 60's (54\% in 2020 vs 30\% in 2019) and those $70+(33 \%$ in 2020 vs 15\% in 2019) also starting using their phones more often to manage their money.

Although managing life using digital tools increased for activities usually performed in-person, those traditional activities already done digitally are still strong. For example, there are differences between age groups among those 50-plus on more traditional activities performed on a smartphone like playing games, an activity done at a higher rate by those in their 50's (59\%) and 60's (48\%) compared to those $70+(35 \%)$, as is getting news and other information where four in five (79\%) of those in their 50's and three-quarters (75\%) of those in their 60 's do, compared to two-thirds (62\%) of those $70+$. 


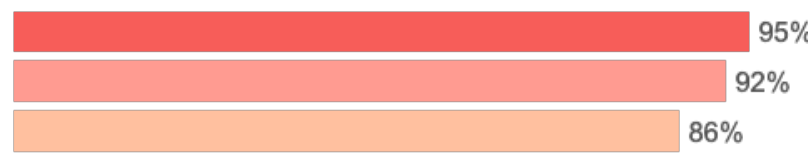

Send or receive instant messages, text messages, or emails

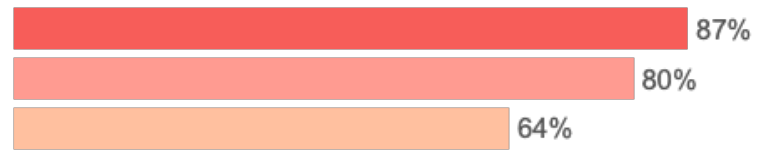

Get directions or traffic information

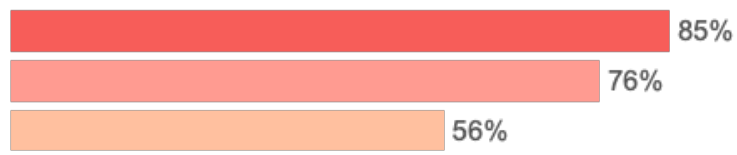

Visit websites or surf the Internet

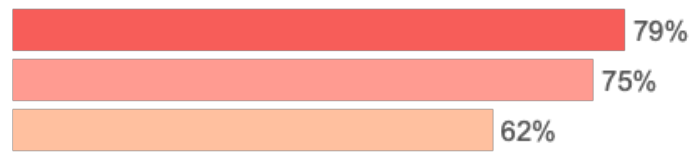

Get news and other information

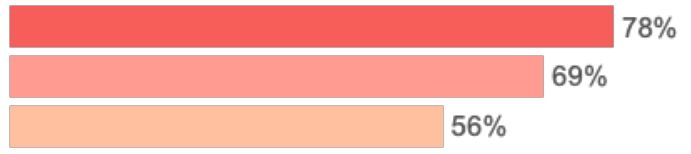

Download or purchase an 'app'

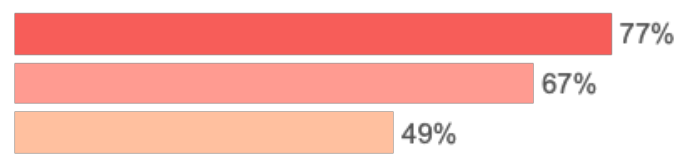

Access a social networking site (e.g. Facebook, Instagram, or Linkedln)

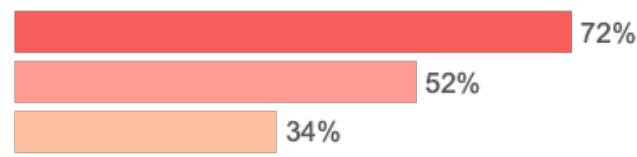

Make a purchase

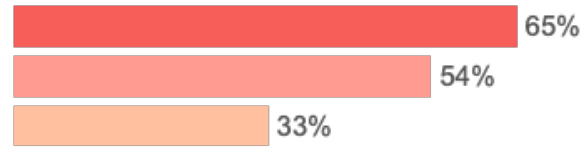

Perform banking or financial transactions

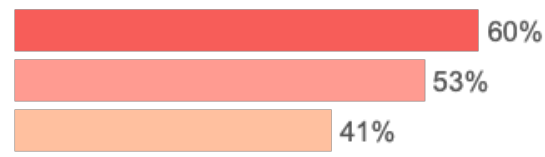

Video chat with friends or family

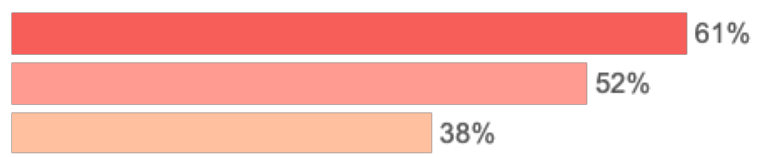

Comparison shop for discounts and deals

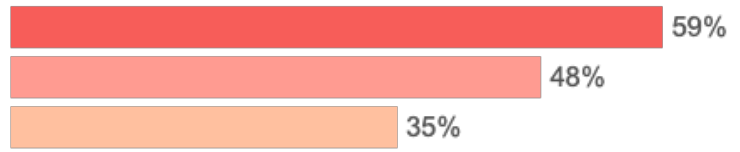

Play a game

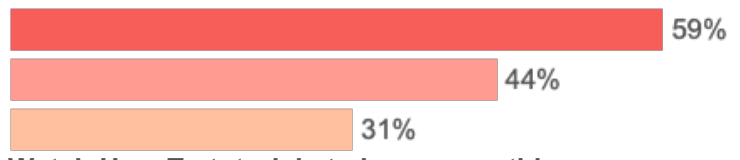

Watch How-To tutorials to learn something new (e.g. YouTube)

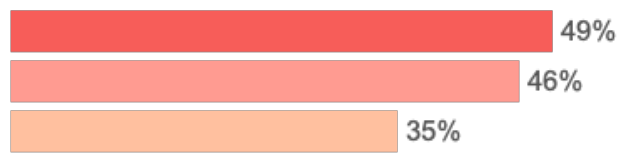

Get health and fitness information

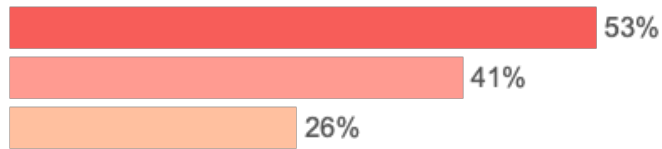

Watch real time social media videos (e.g. Facebook Live)

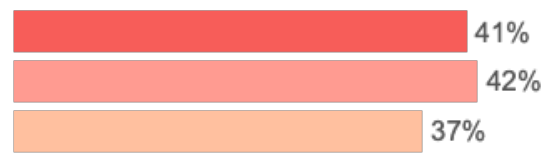

Video chat/talk to your doctor/other medical professional, make medical appointments, order prescriptions, or receive personal healthcare advice

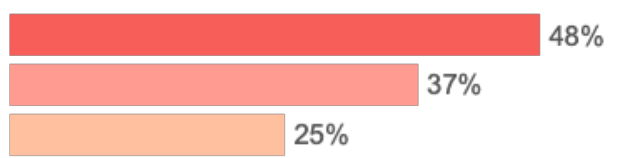

Track your health or fitness via apps or websites (e.g. Apple Health or MyFitnessPal)

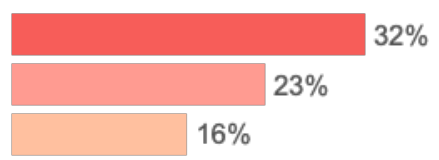

Order groceries for pick up or delivery 


\section{During the pandemic of COVID-19, adults 50-plus embrace technology to stay connected with family and friends, from texting to video chatting}

Among those $70+$, nearly one-third $(31 \%)$ say they call friends and family more now than before the pandemic, compared to those in their 50's (29\%) and 60's (26\%), although those in their 50's and 60's are more likely to use video chat nowadays $(50-59,41 \%$ and $60-69,31 \%)$ than those $70+(19 \%)$. All 50 -plus adults continue to use text, followed by email and video chat as their preferred methods of communication. The 50-plus most often text (86\%) to keep in touch with friends and family at least once a week. Texting is most popular among those in their 50's (93\%) and 60's (90\%), although at three-quarters (73\%), it makes it the most common way those in $70+$ connect with others on a weekly basis.

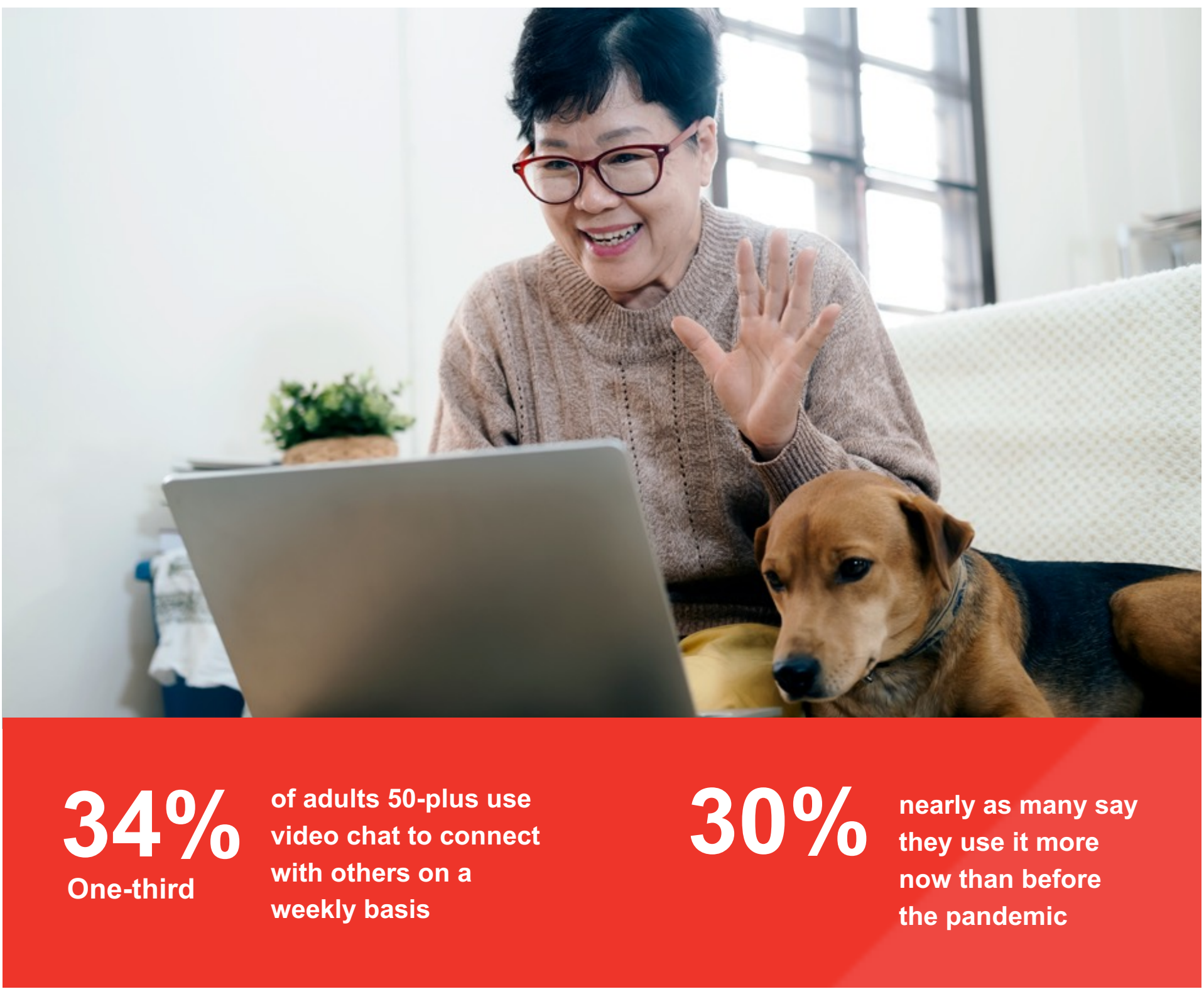

A majority are still using email to connect with others as seven of every ten (71\%) adults 50-plus also mention this medium and use it on a weekly basis, while social media networks trail close behind with almost two-thirds $(65 \%)$ mentioning it as well. Facebook is the top social media network across all age bands (50s: 87\%, 60's: $89 \%, 70+: 89 \%$ ) while the newer platform TikTok skews younger. 
Social media used to connect with friends and family by age group

50-59

60-69

$70+$

f facebook.

(0) Instagram

- YouTube
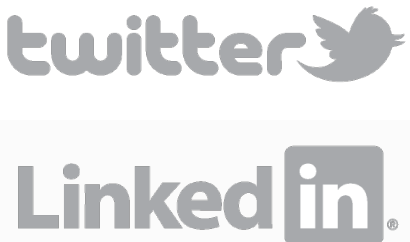

小TikTok

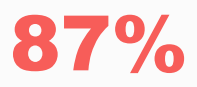

$34 \%$

$15 \%$

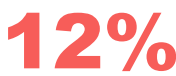

$13 \%$

$6 \%$

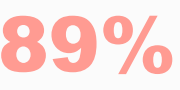

$240 / 0$
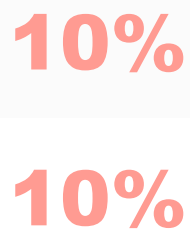

$00 / 0$

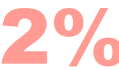

$89 \%$

$16 \%$

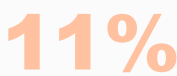

$(0) 0$

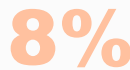

$30 / 0$

While not as prevalent, video chat options - like Skype, WhatsApp, or FaceTime -- have been embraced by those in their 50's as two in five (43\%) use it on a weekly basis, while one-third $(33 \%)$ of those in their 60 's and one-quarter $(24 \%)$ of those $70+$ claim the same frequency of use.

\section{Methods of staying in touch with loved ones - Among those who use weekly}

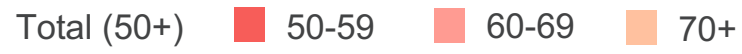
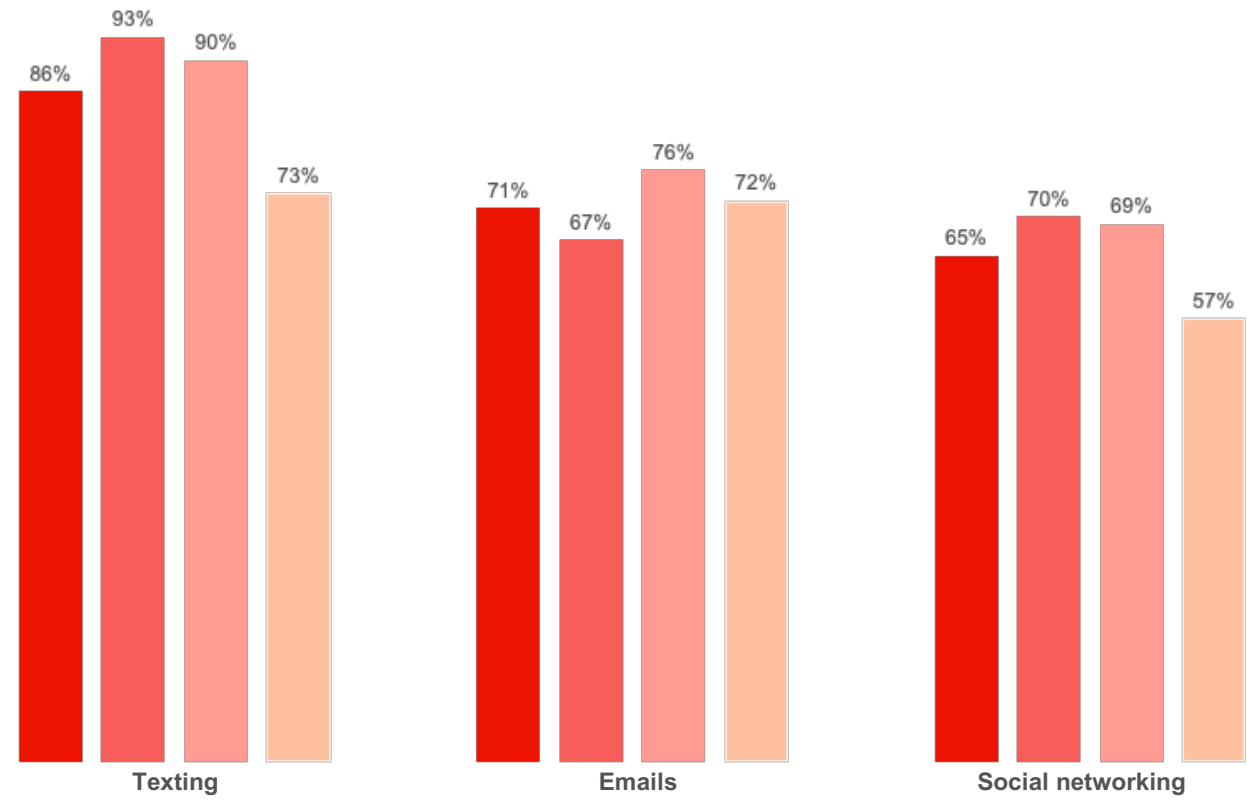

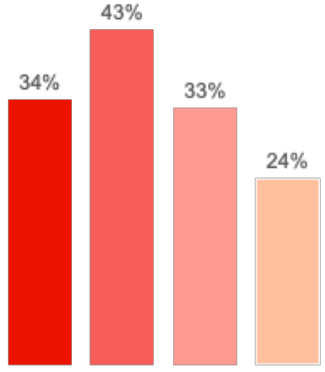

Video chat 


\section{Adults 50-plus increased their streaming habits to access entertainment programming as they move away from network and cable stations}

Adults 50-plus are getting their entertainment programming less and less from network and cable stations (2019, $58 \%$ vs $2020,38 \%$ ) and more and more from streaming channels (2019, $17 \%$ vs $2020,24 \%)$ with onethird $(36 \%)$ viewing entertainment programming through a mix of traditional media and streaming. Those in their 50's stream shows, movies, and series the most as more than one-third (36\%) do so daily, compared to one-quarter of those in their 60's (27\%) and those $70+(25 \%)$, and one-quarter of those in their 50's (24\%) and 60 's $(25 \%)$ who do so a few times a week, compared to $17 \%$ of those $70+$.

Netflix is the streaming service to which most adults 50-plus subscribe (67\%), followed by Amazon Prime Video (55\%) and Hulu (29\%). Disney+, which launched in November of 2019, already has gained one in five $(21 \%)$ of those $50+$. Disney+ enjoys $28 \%$ subscription rate among those in their 50 's, perhaps because children are still at home compared to only $13 \%$ among those $70+$.

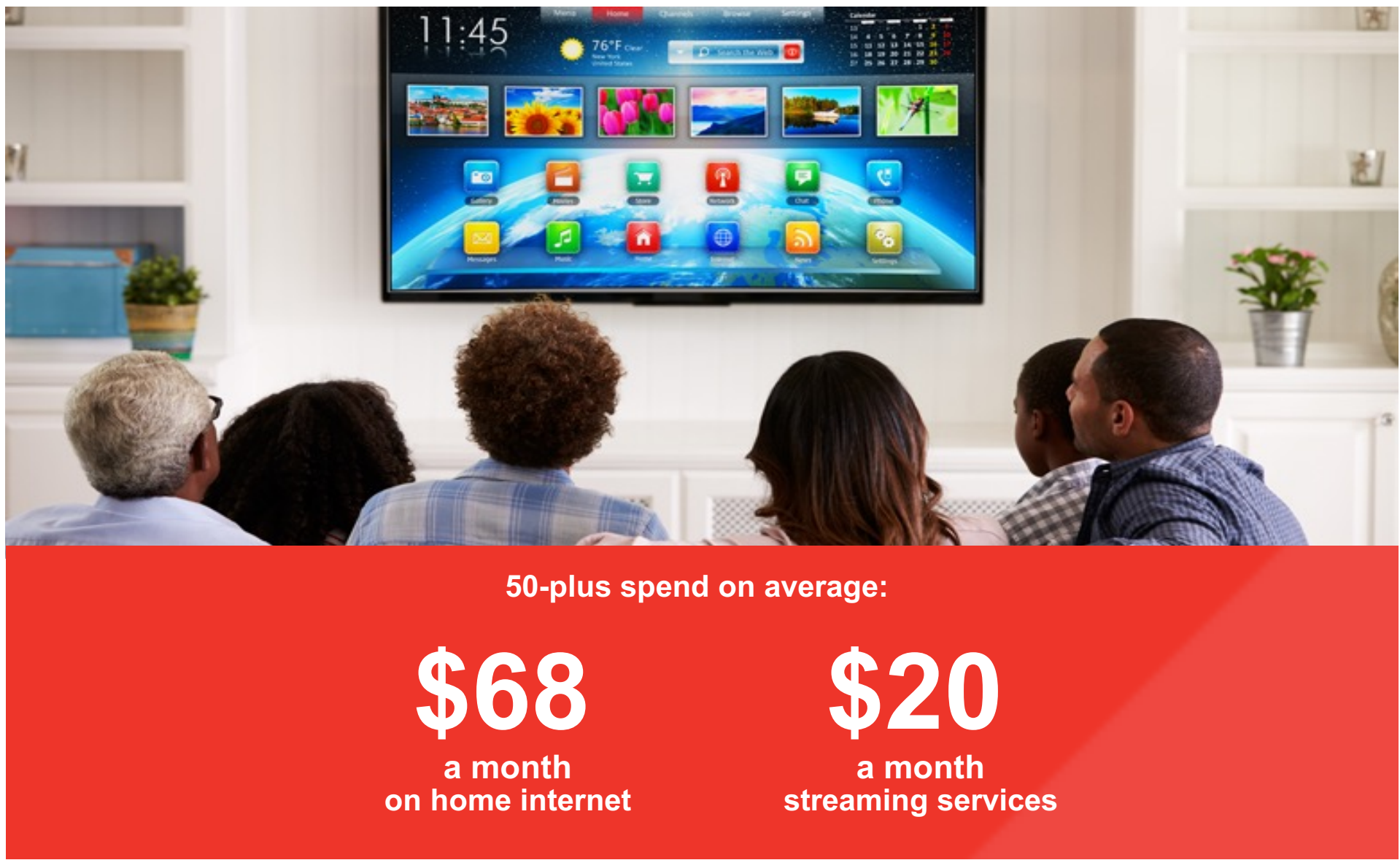

People 50-59 spend $\$ 73$ on average on internet services, more than what is spent by those 60-69 (\$65) and those 70+ (\$64). Those in their 50's and 60's also outspend those 70+ on streaming services like Netflix and Amazon Prime (\$25, 50's; \$19, 60’s; \$13, 70+).

The cost of internet $(61 \%)$ is a bigger concern than access $(41 \%)$ for adults 50 -plus and this trend is even more prevalent among rural 50 -plus adults (64\% and 58\%, respectively). 


\section{Implications}

A behavior which saw an uptick trend is the increased use of tech devices to perform online activities of certain tasks which were traditionally done by adults 50-plus in-person, like online banking and shopping, both of which sharply increased from only one year ago. With most saying they would continue doing these tasks in the future at the same rate once restrictions are lifted, it's important to continue to innovate and make these tasks easier to perform to solidify this change in behavior among activities like banking and shopping.

Those 50-plus are starting to tip the balance towards streaming services to consume entertainment programming, leaving behind networks and cable stations. The increase of Smart TV ownership is a result of this shift as this type of device allows to directly access streaming channels, but it is important to note cost is a concern for adults 50-plus. As more networks launch their own streaming channels, this can become costprohibitive for some and possibly result in subscribing to a select few. Programming is key, as this age cohort seems quick to embrace streaming channels with original content like Disney+, but not so much mainly aggregators of network programming, like Hulu, a possible sign programming from networks, might not be meeting the entertainment needs of people 50-plus.

Right behind cost, privacy concerns and lack of knowledge are at the top of the list of barriers keeping adults 50 -plus from embracing new technologies. Three in five adults (58\%) already feel confident using tech to stay connected in general; it's when it comes to newer tech, like home assistants and smart home tech, adults 50plus wish they had more knowledge. With the desire to learn more about new tech already present, tech companies can leverage this interest and educate them on the different ways these devices can benefit their lives, but most importantly address privacy issues which may be keeping them from embracing technology simply because of misconceptions. With most saying they prefer to learn from people they know, encouraging younger people to bring their older relatives and friends into the tech fold could help gain market share among those 50-plus.

As adults 50-plus continue to embrace technology to stay connected with family and friends, it will be interesting to see if adults 50-plus who truly find these activities convenient will go back to performing them inperson when it becomes safe or if they are simply riding the tech wave due to lack of in-person options. The momentum is here and adults 50-plus are showing their willingness and capacity to embrace technology; now it is up to those developing and marketing technology for this cohort.

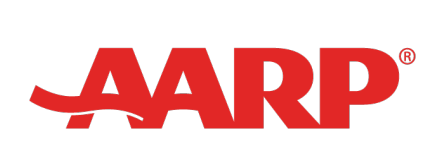

For more information on the survey and methodology please contact: Brittne Kakulla, bkakulla@aarp.org

DOI: doi.org/10.26419/res.00420.011

2021 Tech Trends and the 50-Plus: Top 10 Biggest Trends. Washington, DC: AARP Research, April 2021. DOI: doi.org/10.26419/res.00420.001 